\title{
Spatial variability of soil nutrients in Juglans regia plantations in depressions between karst hills
}

\author{
Qiujin Tan ${ }^{1, a}$, Fuping Zeng ${ }^{2,3, b}$, Haisheng Chen ${ }^{1, \mathrm{c}}$, Zhenshi Qin ${ }^{1, \mathrm{~d}}$, Hu Du ${ }^{2,3, \mathrm{e}}$, \\ Wenlin Wang ${ }^{1, f}$ and Hao Zhang ${ }^{2,3, g}$ * \\ ${ }^{1}$ South Asian Tropical Agricultural Science Research Institute of Guangxi, Longzhou, Guangxi \\ Zhuang Autonomous Region 532415, China \\ ${ }^{2}$ Key Laboratory of Agro-Ecological Processes in Subtropical Region, Institute of Subtropical \\ Agriculture, Chinese Academy of Sciences, Changsha, 410125, China \\ ${ }^{3}$ Huanjiang Observation and Research Station for Karst Ecosystem, Chinese Academy of Sciences, \\ Huanjiang, 547100, China \\ aqiujinT110@163.com, bfpzeng@isa.ac.cn ,'gxnkchhsh741129@163.com, \\ dmacadamia168@126.com, 'ehudu@isa.ac.cn, ${ }^{f}$ nys8810406@126.com, \\ $\mathrm{g}^{*}$ zhanghao@isa.ac.cn(corresponding author)
}

\begin{abstract}
Keywords: coefficient of variation, geostatistical analysis, Kriging interpolation, spatial heterogeneity, walnut

Abstract. To understand the spatial variability of soil nutrients in plantation forest in depressions between karst hills, we examined the characteristics and spatial variability of soil nutrients in Juglans regia plantation in Fengshan County, Southwest China. Most soil nutrients had moderate variability, and coefficients of variation for eight soil chemical characteristics differed according to stand age. All soil nutrient data were normally distributed and could be fitted to Gaussian, spherical, and exponential models, and nutrients showed strong spatial dependence and patterns that differed according to stand age. The distribution of soil nutrients was mainly affected by topography and habitat characteristics (elevation, slope, slope aspect, slope location, and bare rock cover). Our results suggest that stand age as a temporal factor and topography as a spatial factor contribute to patterns of soil nutrients in depressions between karst hills of Southwest China.
\end{abstract}

\section{Introduction}

Soil nutrients can have favorable effects on soil physical, chemical, and biological properties, and nutrient concentrations are good indicators of soil quality and productivity [1,2]. In most plant growth conditions, soil nutrients show high spatial heterogeneity $[3,4]$, which is a result of factors, including parent material, topography, vegetation, climate, and biological conditions [5,6,7]. Land use changes and agriculture also strongly influence soil nutrient concentrations [8,9]. Heterogeneity of soil nutrients can affect plant distribution, and plants influence nutrient availability and distribution by influencing the physical, chemical, and biological properties of soils [10,11]. Therefore, a better understanding of the sources of spatial variability in soil nutrients is important for agricultural and soil management practices.

The karst region covers $5.5 \times 10^{5} \mathrm{~km}^{2}$ in Southwest China and is considered fragile because of its unique geological setting, low environmental carrying capacity, and low tolerance of disturbance [12]. During recent years, forests have degenerated to various degrees into mixed communities at different successional stages as a result of a fast-growing population and intensive soil utilization [13]. In this region, the walnut $J$. regia, a popular food worldwide, has been planted since the $1950 \mathrm{~s}$, and the plantation area has increased dramatically since 2000 with the implementation of China' $\mathrm{s}$ Grain-to-Green Program [14]. J. regia plantations in this region cover more than $1.5 \times 10^{6}$ ha, and experimental field and nursery trials have been conducted in these plantations [15]. Soil nutrient and moisture status are controlling factors in the establishment of $J$. regia plantations and affect the structure, function, and succession of the karst ecosystem [14]. Some researchers have reported on the spatial heterogeneity of soil nutrients and moisture in natural forests in degraded karst areas [16,17], 
but the relationship between environmental factors and soil nutrient distributions in $J$. regia plantations remains unclear.

In this study, we investigated the spatial variability of soil nutrients in different-aged $J$. regia plantations in depressions between karst hills in Fengshan County, China and assessed correlations between nutrients and environmental factors. We determined the characteristics and spatial variability of soil nutrients using classical statistics and geostatistical methods, and we then analyzed the relationships between soil nutrients and plantation age and topography. This study will be favor for understanding the spatial variability of soil nutrients in plantation forest and improvement of soil nutrients management in the karst region.

\section{Material and methods}

Study sites. The study area was located in Fengshan County $\left(24^{\circ} 15^{\prime}-24^{\circ} 49^{\prime} \mathrm{N} ; 106^{\circ} 40^{\prime}-107^{\circ} 2^{\prime} \mathrm{E}\right)$ of northwestern Guangxi Province, Southwest China (Figure 1). The plantation area of J. regia in this county was approximately 12,000 ha in 2014. Sustainable forest management practices including road construction, tending, and the creation of study plots for research and training have been conducted in the experimental forest since 2002. For this study, three stands of different ages $(2,10$, and 33 years) were selected in the experimental forest (Table 1).

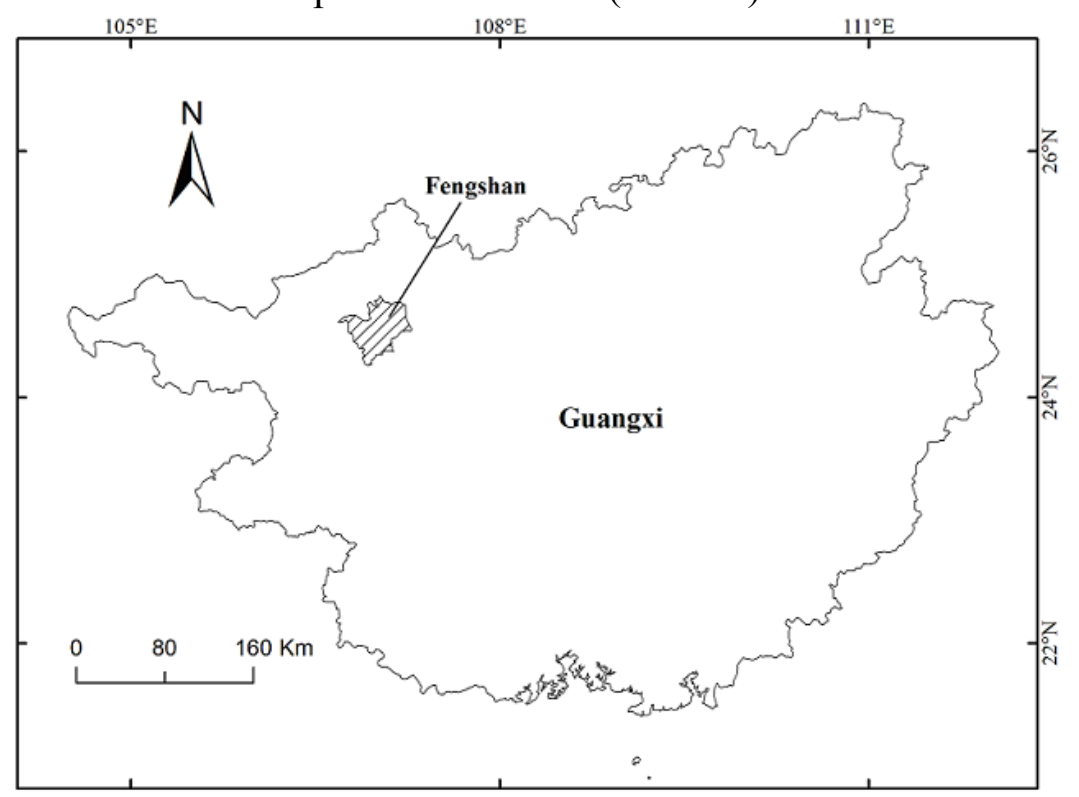

Figure 1. The location of this study area

Table 1 Characteristics of 2-, 10-, and 33-year-old Juglans regia stands

\begin{tabular}{cccc}
\hline Stand Parameters & 2-year-old & 1 10-year-old & 33-year-old \\
\hline Longitude & $106^{\circ} 50^{\prime} 47.04^{\prime \prime}$ & $106^{\circ} 53^{\prime} 41.29^{\prime \prime}$ & $107^{\circ} 02^{\prime} 47.36^{\prime \prime}$ \\
Latitude & $24^{\circ} 38^{\prime} 01.30^{\prime \prime}$ & $24^{\circ} 34^{\prime} 19.03^{\prime \prime}$ & $24^{\circ} 30^{\prime} 14.15^{\prime \prime}$ \\
Altitude $(\mathrm{m})$ & 750 & 727 & 483 \\
Slope $\left({ }^{\circ}\right)$ & 26 & 30 & 21 \\
Stand density $(\mathrm{stems} / \mathrm{ha})$ & $385^{\mathrm{a}} \pm 22$ & $397^{\mathrm{a}} \pm 18$ & $320^{\mathrm{b}} \pm 26$ \\
Soil depth $(\mathrm{cm})$ & 85 & 90 & 85 \\
Bulk density $\left(\mathrm{g} / \mathrm{cm}^{-3}\right)$ & 1.54 & 1.25 & 1.69 \\
Coarse rock fragment $(\%)$ & 29.5 & 23.8 & 26.6 \\
\hline
\end{tabular}

$D B H$ diameter at breast height. Means in a column followed by different lower-case letters are significantly different at $P$ $<0.05$ (one-way ANOVA and LSD test). 
Field sampling and measurements. Three $40 \mathrm{~m} \times 50 \mathrm{~m}$ plots were established for all three stands in a regular slope - depression continuum in October 2014. The plots were established following the standard of the Center for Tropical Forest Science [18,19], and were divided into ten 10 $\mathrm{m} \times 10 \mathrm{~m}$ quadrats. Tree density, tree height $(\mathrm{H})$, and tree diameter at breast height $(D B H)$ were recorded in each plot. We used a $J$. regia growth model developed specifically for southwestern China to estimate tree biomass, which included the biomass of roots, stems, branches, and branchlets [15]. Three $2 \mathrm{~m} \times 2 \mathrm{~m}$ microplots were established within each stand to evaluate understory vegetation. Shrubs and herbs, including roots, were harvested from each microplot.

Eight soil subsamples in each quadrat were collected to a depth of $15 \mathrm{~cm}$ along an S-shaped transect using a soil corer ( $5 \mathrm{~cm}$ diameter). The subsamples were pooled into one composite sample per $10 \mathrm{~m} \times 10 \mathrm{~m}$ quadrat, and the composite samples were air dried and passed through a 2-mm sieve to remove gravel and roots. Soil $\mathrm{pH}$ and nutrient contents, including soil organic matter (SOM), total nitrogen (TN), total phosphorus (TP), total potassium (TK), available nitrogen (AN), available phosphorus (AP), and available potassium (AK) were analyzed in the laboratory according to Bao (2000). Three replicates were analyzed and averaged for each of the analyses to improve the precision of the measurement.

The following topographical features were measured in each quadrat: elevation (Ele), slope aspect (Asp), slope position (Pos), slope angle (Slope), and soil depth (Sp). Elevation was determined using a Garmin GPSmap 60CSX device (Garmin Ltd., Olathe, KS); Asp was determined using an electronic tachometer (NTS-302R: SOUTH Ltd., Guangzhou, China); and Slope was calculated as the mean angular deviation from horizontal of each of the four triangular planes formed by connecting three quadrat corners. Asp, Pos, and Sp were converted to quantitative data following the methods described by [20].

Data analysis. Descriptive statistical analyses and correlation analyses for soil nutrients were performed using SPSS 13.0 for windows (SPSS Inc., Chicago. IL). The mean, standard error (SE), coefficient of variation (CV), and minimum and maximum values were determined for soil nutrient contents. Normality of data was assessed using the Kolmogorov - Smirnov test before geostatistical analysis, and the geostatistical analysis was carried out with GS+ 9.0 [16]. The experimental semivariograms and fitted models were selected according to Refs $[11,13]$. In these semivariograms, the nugget effect $\left(\mathrm{C}_{0}\right)$ represents the undetectable experimental error and field variation within the minimum sampling space, and the sill $\left(\mathrm{C}_{0}+\mathrm{C}\right)$ represents the total spatial variation. The ratio of nugget variance to sill $\left(\mathrm{C}_{0} / \mathrm{C}_{0}+\mathrm{C}\right)$ can be regarded as a criterion for classifying the spatial dependence of soil nutrients. If the ratio is below 0.25 , the variable has strong spatial dependence; if the ratio is between 0.25 and 0.75 , the variable has moderate spatial dependence; otherwise, the variable has weak spatial dependence. Maps of the spatial distribution of soil nutrients were produced using ArcGIS 9.3 for ordinary Kriging interpolation [15].

\section{Results and Discussion}

The statistical parameters of soil nutrient contents in J. regia plantations are presented in Table 2. Most soil nutrients showed moderate variability, and soil $\mathrm{pH}$ had the lowest $\mathrm{CV}$ among the chemical characteristics examined. Soil $\mathrm{pH}$ differed significantly according to stand age. The contents of soil SOM, TN, AP, and AK in 33-year-old plantations were significantly greater than those in the 2- and 10-year-old plantations.

\begin{tabular}{ccccccccc}
\multicolumn{8}{c}{ Table 2 } & Statistical description for soil nutrients in three plots \\
\hline \multirow{2}{*}{ Index } & Ages & $\begin{array}{c}\text { Sample } \\
\text { Number }\end{array}$ & $\begin{array}{c}\text { Min. } \\
\text { Content }\end{array}$ & $\begin{array}{c}\text { Max. } \\
\text { Content }\end{array}$ & $\begin{array}{c}\text { Mean } \\
\text { Content }\end{array}$ & SD & CV(\%) & $\begin{array}{c}\text { Kolmogorov } \\
\text {-Smirnov }\end{array}$ \\
\hline \multirow{2}{*}{$\mathrm{pH}$} & 2 & 30 & 5.72 & 8.10 & $6.92^{\mathrm{c}}$ & 0.58 & 8.34 & 0.62 \\
& 10 & 30 & 6.95 & 8.78 & $7.85^{\mathrm{a}}$ & 0.52 & 6.66 & 0.51 \\
& 33 & 30 & 5.62 & 8.48 & $7.31^{\mathrm{b}}$ & 0.89 & 12.16 & 0.79 \\
$\mathrm{SOM}$ & 2 & 30 & 18.80 & 37.81 & $28.41^{\mathrm{b}}$ & 4.72 & 16.60 & 0.48 \\
$(\mathrm{~g} / \mathrm{kg})$ & 10 & 30 & 14.10 & 58.86 & $25.54^{\mathrm{b}}$ & 7.85 & 30.81 & 0.91 \\
& 33 & 30 & 11.60 & 81.12 & $31.47^{\mathrm{a}}$ & 17.04 & 54.08 & 0.59
\end{tabular}




$\begin{array}{ccccccccc}\mathrm{TN} & 2 & 30 & 1.42 & 2.45 & 1.80^{\mathrm{b}} & 0.25 & 12.06 & 0.47 \\ (\mathrm{~g} / \mathrm{kg}) & 10 & 30 & 1.06 & 3.31 & 1.65^{\mathrm{b}} & 0.41 & 26.86 & 0.87 \\ & 33 & 30 & 1.21 & 3.94 & 2.62^{\mathrm{a}} & 0.63 & 21.94 & 0.66 \\ \mathrm{TP} & 2 & 30 & 0.60 & 1.32 & 0.90^{\mathrm{b}} & 0.11 & 14.72 & 0.72 \\ (\mathrm{~g} / \mathrm{kg}) & 10 & 30 & 0.40 & 1.05 & 0.60^{\mathrm{c}} & 0.13 & 18.63 & 0.75 \\ & 33 & 30 & 0.20 & 2.57 & 1.33^{\mathrm{a}} & 0.72 & 49.85 & 0.76 \\ \mathrm{TK} & 2 & 30 & 11.70 & 24.71 & 18.15^{\mathrm{a}} & 2.13 & 11.74 & 0.90 \\ (\mathrm{~g} / \mathrm{kg}) & 10 & 30 & 6.50 & 24.09 & 14.53^{\mathrm{b}} & 3.45 & 23.47 & 0.64 \\ & 33 & 30 & 11.30 & 27.74 & 15.44^{\mathrm{a}} & 4.47 & 28.61 & 0.82 \\ \mathrm{AN} & 2 & 30 & 88.62 & 274.56 & 178.35^{\mathrm{b}} & 42.41 & 23.78 & 0.61 \\ (\mathrm{mg} / \mathrm{kg}) & 10 & 30 & 73.19 & 216.72 & 114.52^{\mathrm{c}} & 28.89 & 25.22 & 0.81 \\ & 33 & 30 & 101.31 & 375.81 & 221.11^{\mathrm{a}} & 54.99 & 24.87 & 0.90 \\ \mathrm{AP} & 2 & 30 & 2.42 & 18.43 & 6.46^{\mathrm{b}} & 3.77 & 58.44 & 0.96 \\ (\mathrm{mg} / \mathrm{kg}) & 10 & 30 & 2.83 & 14.85 & 6.78^{\mathrm{b}} & 3.10 & 45.68 & 0.92 \\ & 33 & 30 & 2.26 & 134.21 & 61.69^{\mathrm{a}} & 31.76 & 51.48 & 0.56 \\ \mathrm{AK} & 2 & 30 & 47.28 & 773.40 & 143.47^{\mathrm{b}} & 139.43 & 97.17 & 0.84 \\ (\mathrm{mg} / \mathrm{kg}) & 10 & 30 & 69.50 & 505.90 & 167.17^{\mathrm{b}} & 80.26 & 48.01 & 0.92 \\ & 33 & 30 & 56.30 & 738.50 & 360.55^{\mathrm{a}} & 142.45 & 39.51 & 0.64\end{array}$

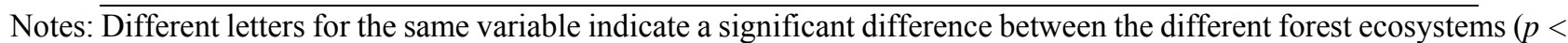
$0.05)$

Table 3 Semivariogram theoretical models and parameters for the soil nutrients in the study area

\begin{tabular}{ccccccccc}
\hline Index & Ages & Model & $\mathrm{C}_{0}$ & $\mathrm{C}_{0}+\mathrm{C}$ & $\mathrm{C}_{0} /\left(\mathrm{C}_{0}+\mathrm{C}\right)$ & $\mathrm{a}(\mathrm{m})$ & $\mathrm{R}^{2}$ & $\mathrm{D}$ \\
\hline & 2 & Spherical & 0.016500 & 0.323000 & 0.0511 & 13.12 & 0.830 & 1.896 \\
$\mathrm{PH}$ & 10 & Guassian & 0.177000 & 0.377000 & 0.4695 & 27.97 & 1.000 & 1.792 \\
& 33 & Spherical & 0.058000 & 0.849000 & 0.0683 & 10.32 & 0.785 & 1.954 \\
& 2 & Spherical & 0.003300 & 0.224600 & 0.0147 & 8.43 & 0.104 & 1.993 \\
$\mathrm{SOM}$ & 10 & Guassian & 0.148000 & 0.731000 & 0.2025 & 12.02 & 1.000 & 1.856 \\
$\mathrm{~g} / \mathrm{kg})$ & 33 & Spherical & 0.296000 & 3.201000 & 0.0925 & 13.51 & 0.721 & 1.903 \\
& 2 & Spherical & 0.000064 & 0.000551 & 0.1162 & 11.41 & 0.417 & 1.962 \\
$\mathrm{TN}$ & 10 & Exponential & 0.000595 & 0.002380 & 0.2500 & 22.98 & 0.999 & 1.870 \\
$\mathrm{~g} / \mathrm{kg})$ & 33 & Spherical & 0.000100 & 0.003560 & 0.0281 & 15.36 & 0.932 & 1.824 \\
& 2 & Guassian & 0.000003 & 0.000146 & 0.0205 & 9.54 & 0.522 & 1.994 \\
$\mathrm{TP}$ & 10 & Spherical & 0.000011 & 0.000133 & 0.0827 & 12.17 & 0.935 & 1.909 \\
$(\mathrm{~g} / \mathrm{kg})$ & 33 & Exponential & 0.002850 & 0.012040 & 0.2367 & 21.30 & 0.708 & 1.867 \\
& 2 & Spherical & 0.045510 & 0.097800 & 0.4653 & 24.81 & 0.916 & 1.869 \\
$\mathrm{TK}$ & 10 & Exponential & 0.039178 & 0.092546 & 0.4233 & 24.81 & 0.994 & 1.954 \\
$(\mathrm{~g} / \mathrm{kg})$ & 33 & Spherical & 0.004400 & 0.181800 & 0.0242 & 11.23 & 0.595 & 1.945 \\
& 2 & Exponential & 967.090000 & 1745.960000 & 0.5539 & 24.81 & 0.449 & 1.990 \\
$\mathrm{AN}$ & 10 & Spherical & 18.000000 & 954.300000 & 0.0189 & 14.88 & 0.952 & 1.837 \\
$(\mathrm{mg} / \mathrm{kg})$ & 33 & Spherical & 345.000000 & 3390.000000 & 0.1018 & 12.31 & 0.784 & 1.920 \\
& 2 & Spherical & 0.140000 & 12.870000 & 0.0109 & 10.22 & 0.807 & 1.952 \\
$\mathrm{AP}$ & 10 & Exponential & 5.980000 & 8.350000 & 0.7161 & 24.81 & 0.978 & 1.852 \\
$(\mathrm{mg} / \mathrm{kg})$ & 33 & Exponential & 378.000000 & 1013.000000 & 0.3731 & 25.65 & 0.922 & 1.891 \\
& 2 & Guassian & 2900.000000 & 3933.000000 & 0.7373 & 28.56 & 1.000 & 1.476 \\
$\mathrm{AK}$ & 10 & Exponential & 3026.087000 & 5058.259000 & 0.5983 & 24.81 & 0.693 & 1.995 \\
$(\mathrm{mg} / \mathrm{kg})$ & 33 & Spherical & 480.000000 & 20800.000000 & 0.0231 & 10.16 & 0.995 & 1.943 \\
\hline & & & & & & & &
\end{tabular}

Notes: $C_{0}, C_{0}+C$, a, and $D$ represent nugget, sill, range, and fractal dimension, respectively 

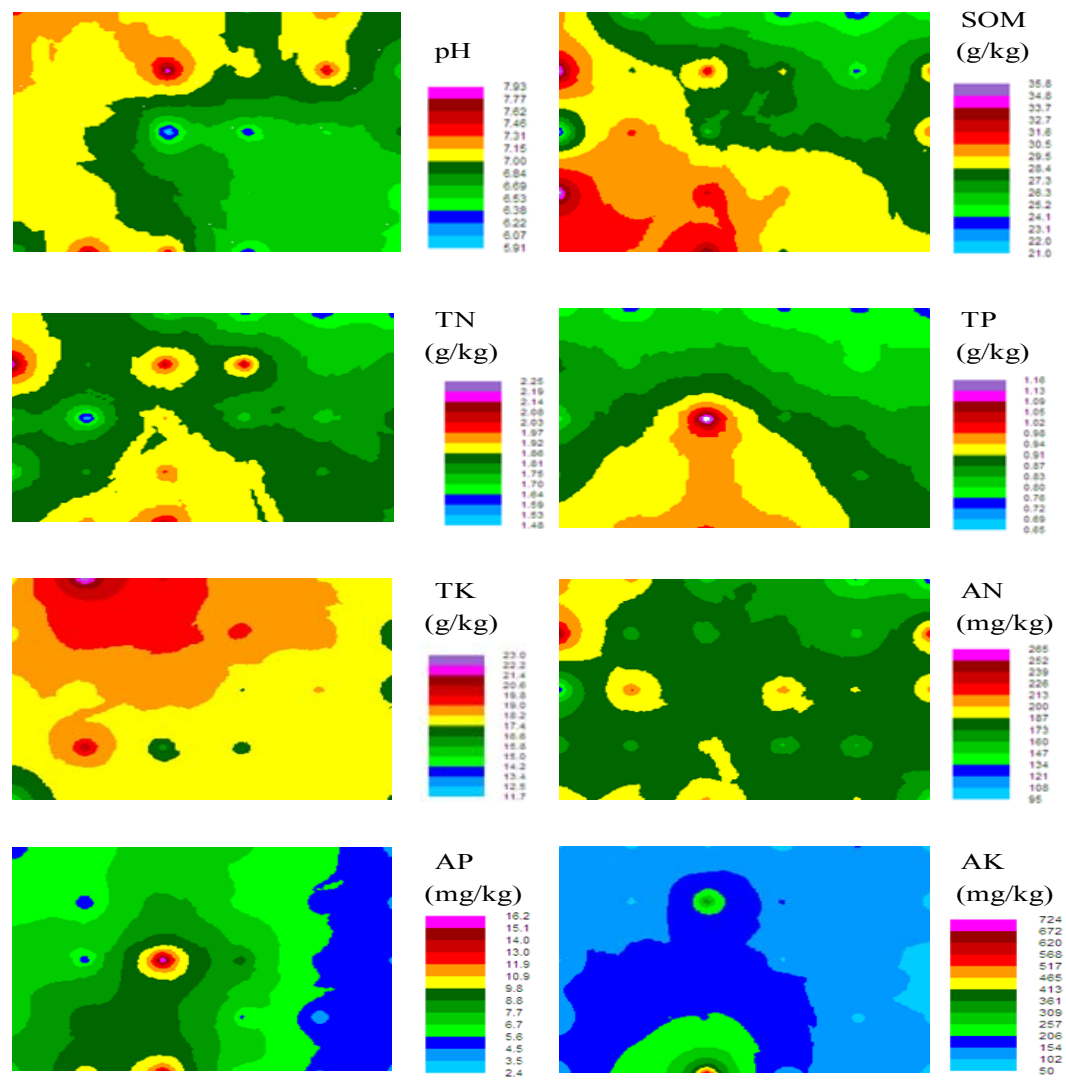

Figure 2. Kriging maps showing spatial distribution of soil nutrients for 2-year-old Juglans regia stands
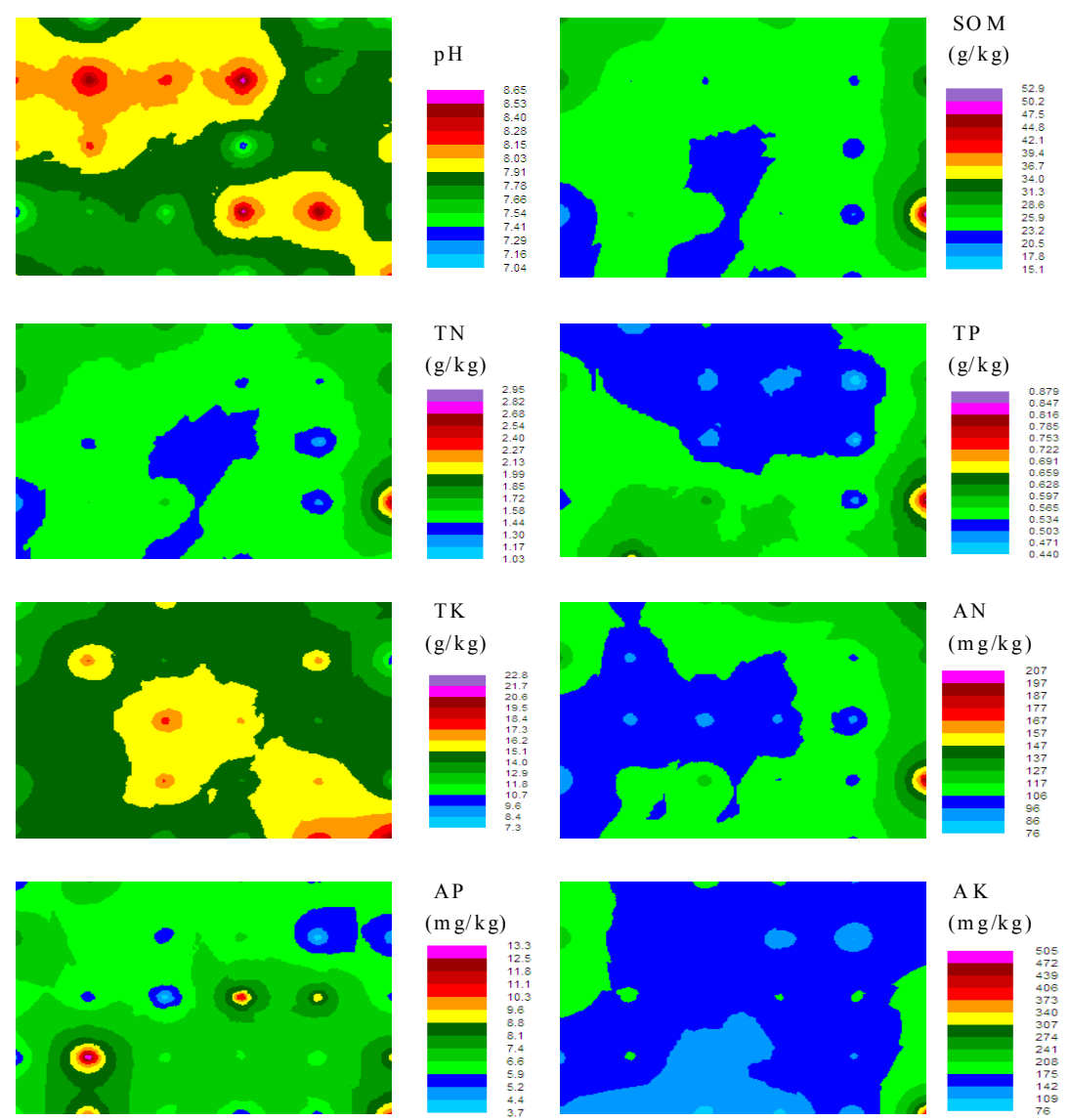

Figure 3. Kriging maps showing spatial distribution of soil nutrients for 10-year-old Juglans regia stands 

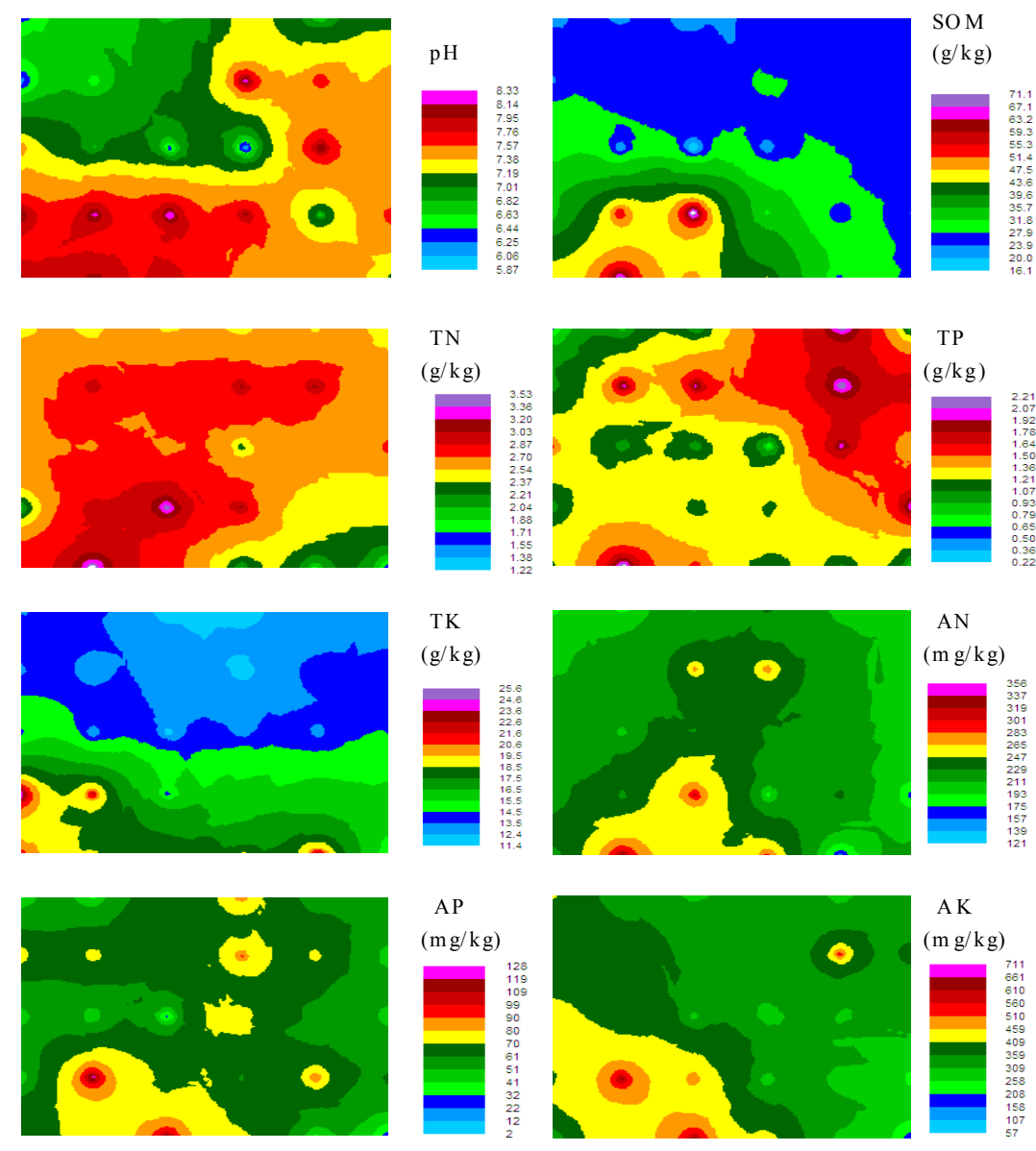

Figure 4. Kriging maps showing spatial distribution of soil nutrients for 33-year-old Juglans regia stands

Table 4 Correlationship between soil nutrients and topography factors

\begin{tabular}{cccccc}
\hline Soil nutrients & Elevation & Slope & Slope aspect & Slope location & Rock-bareness rate \\
\hline $\mathrm{pH}$ & $0.37^{*}$ & -0.16 & -0.08 & $-0.38^{*}$ & $-0.41^{* *}$ \\
$\mathrm{SOM}(\mathrm{g} / \mathrm{kg})$ & -0.11 & 0.05 & 0.05 & $0.54^{* *}$ & -0.16 \\
$\mathrm{TN}(\mathrm{g} / \mathrm{kg})$ & $-0.43^{*}$ & 0.14 & 0.17 & $0.43^{*}$ & $-0.42^{* *}$ \\
$\mathrm{TP}(\mathrm{g} / \mathrm{kg})$ & $-0.75^{* *}$ & $-0.49^{* *}$ & $0.54^{* *}$ & $0.79^{* *}$ & $0.59^{* *}$ \\
$\mathrm{TK}(\mathrm{g} / \mathrm{kg})$ & 0.09 & 0.09 & -0.13 & 0.16 & 0.08 \\
$\mathrm{AN}(\mathrm{mg} / \mathrm{kg})$ & -0.14 & 0.13 & $0.45^{*}$ & -0.12 & $0.47^{* *}$ \\
$\mathrm{AP}(\mathrm{mg} / \mathrm{kg})$ & -0.08 & -0.03 & -0.19 & $0.41^{*}$ & -0.05 \\
$\mathrm{AK}(\mathrm{mg} / \mathrm{kg})$ & $-0.58^{* *}$ & $-0.47^{* *}$ & $0.42^{*}$ & $-0.58^{* *}$ & $0.48^{* *}$ \\
\hline Note: ${ }^{*} \mathrm{P}<0.05,{ }^{* *} \mathrm{P}<0.01$ & & & &
\end{tabular}

The Kolmogorov - Smirnov test showed that all soil nutrient data were normally distributed (Table 2). Semivariograms of the soil nutrients fit well to Gaussian, spherical, and exponential models. The coefficients of determination $\left(\mathrm{R}^{2}\right)$ for all variables were greater than 0.417 (Table 3 ), which suggested that the models accurately reflected the spatial characteristics of soil nutrients. All semivariogram models showed strong spatial dependence for most nutrients $\left(\mathrm{C}_{0} / \mathrm{C}_{0}+\mathrm{C}<0.25\right)$. There was moderate spatial dependence for TK, AN, and $\mathrm{AK}$ in 2-year-old plantations; for $\mathrm{pH}, \mathrm{AP}$, and $\mathrm{AK}$ in 10-year-old plantations; and for AP in 33-year-old plantations $\left(0.25<\mathrm{C}_{0} / \mathrm{C}_{0}+\mathrm{C}<0.75\right)$. Strong spatial autocorrelation of soil chemical characteristics suggested that structural factors (e.g., topography, parent material, and climate) rather than random factors contribute to this spatial variability $[13,20]$. Moderate spatial autocorrelation of some nutrients suggested the influence of both structural and random factors [15]. In addition, Kriging interpolation reflected the spatial patterns of nutrients in soil (Figures 2-4), and the patterns differed for each stand age. 
Table 4 shows the correlations between soil nutrient contents, topographic factors, and habitat characteristics in the karst depression. There were significant positive correlations between soil $\mathrm{pH}$ and elevation, and significant negative correlations between soil $\mathrm{pH}$ and slope aspect, slope location, and bare-rock ratio. TN, TP, and AK had significant negative correlations with elevation. TP and AK had significant negative correlations with slope and were positively correlated with slope aspect. SOM, TN, TP, and AP were significantly and positively correlated with slope location, and AP was significantly and negatively correlated with slope aspect. TN had a significant negative correlation with bare-rock ratio, while $\mathrm{TP}, \mathrm{AN}$, and $\mathrm{AK}$ had significant positive correlations with bare rock.

Topography, an important soil formation factor, can affect local climate via the distribution of solar radiation and precipitation and affects soil depth and nutrient content $[17,21,22]$. Previous studies showed that TP, TK, AP, and $\mathrm{pH}$ decrease with increasing elevation and decreasing cover of bare rock and that SOM increases with increasing elevation, which indicated that the spatial distribution and variability of soil nutrients was mainly affected by topographic factors and habitat characteristics [16]. Here, our results also showed that the spatial distribution of soil nutrients was closely related to topography. Some of our findings were not consistent with those of previous studies, which suggests that the relationship between soil nutrients and topographic factors is complicated in karst areas. Moreover, the role of vegetation, microorganisms, climate, and other factors influence the distribution of soil nutrients in karst area should be considered in further research.

\section{Conclusions}

(1) In depressions between karst hills, most soil nutrients have moderate variability, and coefficients of variation values in the eight soil chemistry characteristics were different in three stand ages. All soil nutrients are a normal distribution and can be fitted well as the gaussian, spherical, and exponential models. Soil nutrients showed strong spatial dependence in J. regia plantations that varied in age from 2 to 33 years.

(2) The patterns of nutrient distribution differed among the stands and were mainly affected by and topography and habitat characteristics in the karst region of Southwest China

\section{Acknowledgements}

This research was supported by the Chinese Academy Sciences Action Plan for the Development of Western China (KZCX2-XB3-10); Key State Basic Research Development Program of China (2015CB452703), the Strategic Priority Research Program-Climate Change: Carbon Budget and Related Issues of the Chinese Academy of Sciences (XDA05070404 and XDA05050205), the National Natural Science Foundation of China (Nos. 31370485, 31370623, 31400412 and 41471233); the "100 talents program" of the Chinese Academy of Sciences (2060299, Y251101111); the Western Light Program of Talent Cultivation of the Chinese Academy of Sciences and Guangxi Provincial Program of Distinguished Expert in China.

\section{References}

[1] A. Bauer and A.L. Black: Soil Science Society of America Journal, Vol. 58 (1994) No.1, pp.185 $-193$.

[2] S.D. Bao: Soil and agricultural chemistry analysis(Agriculture Press of China, Beijing, China 2000).

[3] F.T. Maestre, J. Cortina, S. Bautista, J. Bellot and R. Vallejo: Ecosystems, Vol. 6 (2003) No.7, pp. $630-643$.

[4] A.T. Austin, L. Yahdjian, J.M. Stark, J. Belnap, A. Porporato, U. Norton, D.A. Ravetta and S.M. Schaeffer: Oecologia, Vol. 141 (2004) No.2, pp.221 - 235. 
[5] B.J. Carter and E.J. Ciolkosz: Geoderma, Vol. 49 (1991) No.3-4, pp.199 - 213.

[6] C.E. Johnson, J.J. Ruiz-Mendez and G.B. Lawrence: Soil Science Society of America Journal, Vol. 64 (2000) No.5, pp.1804 - 1814.

[7] S. Wang, X. Wang and Z. Ouyang: Journal of Environmental Science, Vol. 24 (2012) No.3, pp. $387-395$.

[8] M. Lemenih, E. Karltun and M. Olsson: Agriculture Ecosystem \& Environment, Vol. 109 (2005) No.1-2, pp. 9 - 19.

[9] V. Geissen, R. Sánchez-Hernández, C. Kampichler, R. Ramos-Reyes, A. Sepulveda-Lozada and S. Ochoa-Goana: Geoderma, Vol. 151 (2009) No.3-4, pp. 87 - 97.

[10] L. Augusto, J. Ranger, D. Binkley and A. Rothe: Annals Forest Science, Vol. 59 (2002) No.3, pp. $233-253$.

[11] J.M. Jacobs, B.P. Mohanty, E. Hsuc, D. Miller and X. SME: Remote Sensing of Environment, Vol. 92 (2004) No.4, pp.436 - 446.

[12] Y.P. Nie, H.S. Chen, K.L. Wang and J. Yang: Journal of Hydrology, Vol. 420 (2012) No.14, pp. $264-274$.

[13] H. Du, W.X. Peng, T.Q. Song, F.P. Zeng, K.L. Wang, M. Song and H. Zhang: Plant Biosystem, Vol. 149 (2015) No.1, pp.121 - 130.

[14] K. Luo, X.J. Pan, Z. Guo and W.M. Zhong: Guizhou Agriculture Science, Vol. 40 (2012) No.2, pp.168 - 170. (In Chinese)

[15] W.G. Zhang, W.D. Xie, G.X. Jiang, J.Y. Lai, H.M. Shi and H.W. Hu: Journal of Central South University Forest \& Technology, Vol. 31 (2011) No.8, pp. 96 - 101. (In Chinese)

[16] W. Zhang, H.S. Chen, K.L. Wang, Y.R. Su, J.G. Zhang and A.J. Yi: Science of Agriculture Sinica, Vol. 6 (2006) No.3, pp.1829 - 1835. (In Chinese)

[17] Z.H. Zhang, G. Hu, J.D. Zhu, D.H. Luo and J. Ni: Ecological Research, Vol. 25 (2010) No.6, pp. $1151-1160$.

[18] H. Zhang, T.Q. Song, K.L. Wang, H. Du, Y.M. Yue, G.X. Wang and F.P. Zeng: Ecological Engineering, Vol. 73 (2014) No.3, pp.184 - 191.

[19] H. Zhang, T.Q. Song, K.L. Wang, G.X. Wang, J.X. Liao, G.H. Xu and F.P. Zeng: Environmental Research Letters, Vol. 10 (2015) No.4, pp.044014

[20] H. Du, K.L. Wang, W.X. Peng, F.P. Zeng, T.Q. Song, H. Zhang and S.Y. Lu: Chinese Geographical Science, Vol. 24 (2014) No.2, pp.163 - 179.

[21] S.J.Liu, W.Zhang, K.L.Wang, F.J.Pan, S.Yang and S.S.Yan: Science of the Total Environment, Vol. 522 (2015) No.1, pp.52 - 58.

[22] X.K.Qi, K.L.Wang and C.H.Zhang: Ecological Engineering, Vol. 54 (2013) No.1, pp.245 - 253. 